\title{
Infra-red images of heat field around a linear heater and sap flow in stems of lime trees under natural and experimental conditions
}

\author{
Nadezhda NADEZHDINA $^{\mathrm{a} *}$, Helmut TRIBUTSCH ${ }^{\mathrm{b}}$, Jan ČERMÁK ${ }^{\mathrm{a}}$

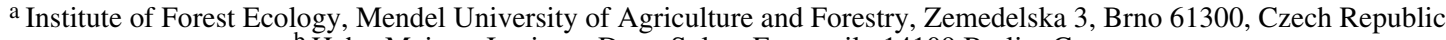 \\ b Hahn-Meitner Institute, Dept. Solare Energetik, 14109 Berlin, Germany
}

(Received 26 February 2003; accepted 20 August 2003)

\begin{abstract}
The heat field deformation method, HFD, for sap flow measurements was applied under field conditions simultaneously with the infra-red imaging of the smoothed stem surface in two lime (Tilia cordata Mill.) trees. Deformation of the heat field generated in the stems by the linear heater was measured by thermocouples, installed in axial and tangential directions around the heater in different xylem depths. The frontal and radial views of the heat field were visualized at the same time by the infra-red, IR, camera under conditions of zero-flow and moving sap. The IR-technique basically underlines the established interpretation of sap flow dynamics, but contributes by a more complex and visualized picture. The IR also shows directly the xylem anisotropy. The ability of HFD-method for measurements of bi-directional sap flow rates and flows approaching zero was confirmed by simultaneous comparing with IR-images. Fast responding and capabilities of HFD-method for studying tree architecture and function were demonstrated.
\end{abstract}

cutting / bi-directional, low and "zero"-flow / flow redistribution / heat field deformation method

Résumé - Images infra-rouges du champ calorifique autour d'un appareil de chauffage linéaire et flux de sève dans des troncs de tilleul en conditions naturelles et expérimentales. La méthode de déformation du champ calorifique (HFD) a été appliquée à des mesures du flux de sève en conditions naturelles, simultanément avec la photographie infra-rouge de la surface du tronc lisse de deux arbres. La déformation du champ calorifique produite dans les troncs par chauffage linéaire a été mesurée avec des thermocouples installés dans des directions axiales et tangentielles autour du chauffage à différentes profondeurs de xylème. Les vues frontales et radiales du champ calorifique ont été simultanément visualisées par une caméra infrarouge, IR, dans des conditions de flux nul ou non nul de sève. La technique IR appuie l'interprétation établie de la dynamique du flux de sève, mais fournit aussi une information plus complexe et plus imagée, qui pourrait être employée pour l'optimisation du positionnement des sondes thermiques. La détection IR montre également l'anisotropie du xylème (axiale et tangentielle), qui a été mesurée et représentée. Les capacités de la méthode HFD, pour des mesures du flux bi-directionnel de sève et des flux extrêmement faibles approchant zéro (tels que la re-saturation des flux pendant la nuit), ont été confirmées par comparaison simultanée avec des images IR. La rapidité ainsi que les possibilités uniques qu'offre la méthode HFD pour étudier l'architecture et le fonctionnement de l'arbre ont été démontrées. Pendant les expériences de découpage, la redistribution du flux dans le parcours du xylème a pu être étudiée.

découpage / bi-directionnel, faible et « zéro »-flux / redistribution du flux / méthode de déformation du champ calorifique

\section{INTRODUCTION}

Good knowledge of heat distribution around sap flow measuring points when using thermal methods with internal heating is a prerequisite for understanding heat field deformation by moving sap and determination of right sensor geometry. However measuring the heat field when using a higher number of thermometers is difficult, first of all because conducting pathways would be severely damaged. Application of infra-red technology introduced by Anfodillo et al. [1,2] and applied for further sap flow studies [8] has a great advantage in this respect. We focused in this paper on simultaneous measurement of temperature gradients by thermocouples, inserted in the sap flow sensors and situated within the conductive xylem around a linear heater, and by the infra-red camera, focused on the selected and smoothed stem surfaces. We wanted to compare both techniques under well defined experimental conditions in order to identify advantages and shortness each of them.

Particularly we tried to answer following methodical questions: visualization of the frontal and the radial view of heat field around the linear heater in a real tree stem taking place during usual diurnal changes of sap flow; deformation of heat field after abrupt changes of heating (when the heater is switched on and off) under conditions of zero-flow and moving sap; deformation of heat field when sap flow was interrupted abruptly (cutting experiments under

\footnotetext{
* Corresponding author: nadezdan@mendelu.cz
} 
continuous heating); verification of HFD-method for measuring bi-directional and very low flows.

At the same time, combination of applied two independent methods of measurement temperature gradients around the linear heater should lead to new insights useful for further better theoretical understanding of the relation between measurable parameters of the heat field and sap flow and for methodical aspects of sap flow techniques.

\section{MATERIALS AND METHODS}

\subsection{Site and sample trees}

Experiments were performed in sample trees situated in the small park of the Hahn-Meitner Institute in Berlin, Germany during August 1999. Two lime sample trees (Tilia cordata Mill.) with similar diameter at breast height (Tilia_1: $15.3 \mathrm{~cm}$ and Tilia_2: $14.8 \mathrm{~cm}$ ) were selected for the study.

The first sample tree - Tilia_1 was prepared for taking frontal images of the heat field around the heater. This was achieved by cutting off the outer segment of the stem $(20 \mathrm{~cm}$ long) down to the depth of $2.6 \mathrm{~cm}$ from the northern stem side (Fig. 1, upper panel). The xylem surface, opened this way, was then smoothed by a sharp knife and the IR-camera was focused on the smooth surface. The multi-point HFD sap flow sensor was installed from the opposite (southern) side of stem, so that the tip of the long heater reached the smooth surface. The heated (hot) point visible on the smoothed stem surface occurred at a depth corresponding to the middle sapwood approximately. The heat field generated by the linear heater (heated hypodermic needle) was then simultaneously recorded by the series of multi-point thermometers and by the IR-camera, which visualized its frontal image (Fig. 1, upper panel).

The second sample tree - Tilia_2 was prepared to get the radial image of heat field around the heater (Fig. 1, middle panel). A bigger part of the stem was cut-off (down to the depth of $4.5 \mathrm{~cm}$ from the eastern side of the stem) and its surface was smoothed as in the previous case. The same radial sap flow sensor was installed in the stem, but in parallel to the smooth stem surface. This way it was made possible to monitor the radial (parallel to the stem radius) IR-images of the heat field periodically and to get a continuous record of sap flow at the same time.

\subsection{Sap flow measurements}

Sap flow was measured by the heat field deformation (HFD) method $[16,19]$. Sensors consisted of a long linear heater and two pairs of thermocouples, of which one was placed symmetrically $1.5 \mathrm{~cm}$ up and down from the heater (measured symmetrical temperature difference $\left.\mathrm{dT}_{\text {sym }}\right)$, while the other was placed asymmetrically at a short distance $(1.0 \mathrm{~cm})$ on one side of the heater (measured asymmetrical temperature difference $\mathrm{dT}_{\mathrm{as}}$ ) [21]. Reference ends of the thermocouples were at the same height below the heater. The heater and the thermocouples were mounted in stainless steel hypodermic needles (always six pairs of the thermocouples per needle were applied). The ratio of both measured temperature gradients $\left(\mathrm{dT}_{\mathrm{sym}} / \mathrm{dT}_{\mathrm{as}}\right)$, the geometry of the measuring point and appropriate physical constants were applied for calculation of the sap flow [19].

\subsection{Infra-red imaging}

The infrared camera (Model 600 IR Imaging Radiometer from Inframetrics, 1990) with temperature resolution of $0.1^{\circ} \mathrm{C}$, spectral band- pass 8-12 micrometer and detector $\mathrm{HGCdTe} / 77^{\circ} \mathrm{C}$ was cooled by liquid nitrogen. The camera was mounted on a tripod and focused on the smoothed xylem surface to take heat field images (Fig. 1, lower panel). No filters were used, but a silicon teleobjective was applied. Temperature scale was about $4{ }^{\circ} \mathrm{C}$ within the range 15 to $22^{\circ} \mathrm{C}$. Several hundreds of IR images were taken periodically. The actual terms of recording were selected in correspondence with the continuous record of sap flow.

\subsection{Cutting experiments}

\section{Tilia_1}

Tilia_1 was treated in four subsequent steps in order to see in detail the reaction of the tree, recorded by different techniques from two opposite sides of the tree stem: (1) First, one main branch of the crown was cut from two opposite sides approximately until pith (with distance $25 \mathrm{~cm}$ between both cuttings) at $15.38 \mathrm{~h}$ (Fig. 2, left) and then (2) it was removed $11 \mathrm{~min}$ after the cutting (Fig. 2, middle). (3) The main stem was cut below the heater (from the same side, where IR images were taken) 14 min later after branch removal (Fig. 2, right scheme and photo). (4) Finally the main stem was cut above the heater $8 \mathrm{~min}$ after the first cut from the same side of the stem (Fig. 2, right scheme and photo).

\section{Tilia_2}

In order to get the true zero sap flow in Tilia_2, its main stem was cut down to the pith $20 \mathrm{~cm}$ above the sensor from one side at $15.15 \mathrm{~h}$ and subsequently $10 \mathrm{~cm}$ below the sensor from the opposite side of the stem referring to the radial sensor at $15.38 \mathrm{~h}$ (Fig. 1, middle panel).

\section{RESULTS AND DISCUSSION}

\subsection{Heat field around the heater under conditions of zero-flow}

The frontal view of the heat field under zero sap flow appeared as a rather symmetrical ellipse, whose axis length in axial and tangential directions reached the ratio of about 1.3:1, respectively (Fig. 3, upper panel, the first left image) due to different heat conductivities in the corresponding directions.

IR-images taken along the heater installed in radial direction (reaching from cambium on one side of the stem almost to the bark on the opposite side) indicated a corresponding heat field, which approached a symmetrical form (when looking up and down the heater) under zero sap flow (Fig. 3, lower panel, the first left image). The clearly distinguishable warm zone around the heater disappeared gradually (i.e., heat field homogenized with its surrounding) when heating was switched off. The disappearing hot point remained on the same place at the heater axis on the frontal image. Similarly the disappearing warm zone remained symmetrical along the axis of the heater at the radial images of the smoothed stem surface (see Fig. 3).

\subsection{Heat field around the heater under conditions of moving sap}

\subsubsection{Frontal view under switching off and on the heating}

The heat field responded to switching-off the heating by gradual homogenizing with the surroundings, but it was also carried upwards by the moving sap (Fig. 4, upper images) 

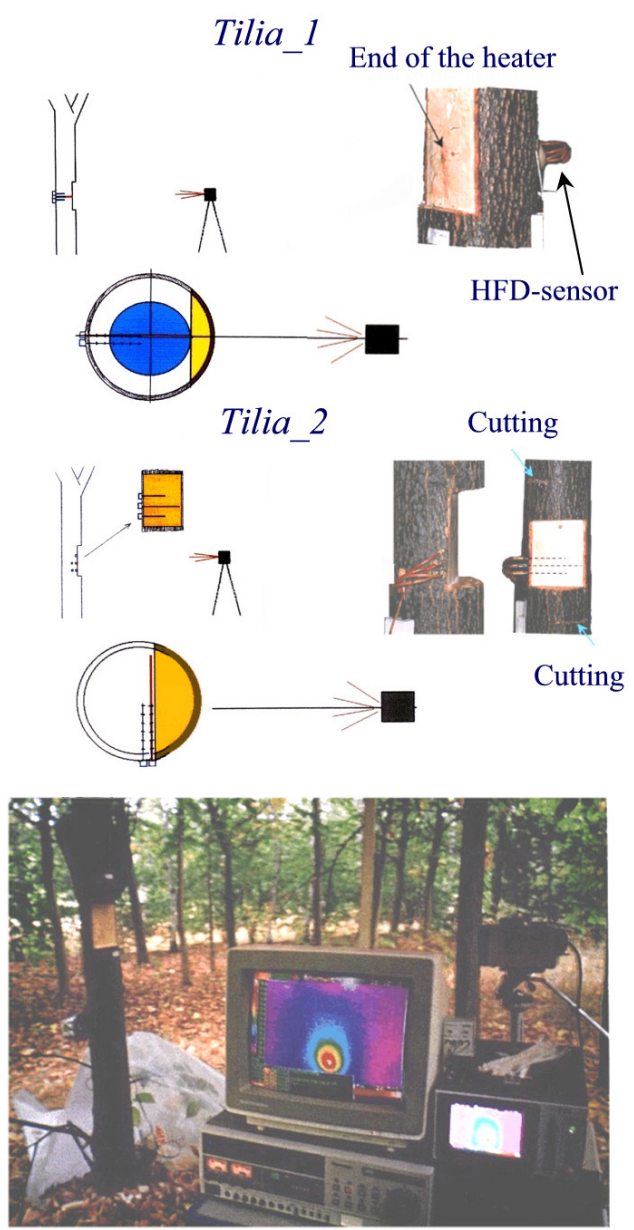

Figure 1. Upper panel (Tilia_1): Schemes and photo of the lime sample tree stem prepared for taking infra-red images of heat field around a linear heater visible in frontal direction: cross-section of the tree stem with the radial sap flow sensor installed from the opposite side of stem and the infra red camera focused on the smoothed stem surface. Blue color limits zone with similar flow rates from both opposite sides of stem (visible by infra-camera and measured between the second and third outer thermocouples of the radial sensor). Two nails were installed on the smoothed surface of the stem as referent ends: one on the distance of $3 \mathrm{~cm}$ apart from the heater and other on the distance of $3 \mathrm{~cm}$ above the first nail. Middle panel (Tilia_2): Similar schemes and photos of the sample tree Tilia_2. Radial sap flow sensor was installed in parallel to the smoothed stem surface, so that the IR-camera "saw" heat field in radial direction. Scheme of cutting experiments carried out with Tilia_2 is also shown in the right photo. A nail was installed on the smoothed surface of the stem as referent end, marked localization of pith. Yellow areas in both stem cross-sections correspond to cut-off parts of stems. Lower panel: General view of experimental place with sample tree and IRequipment.

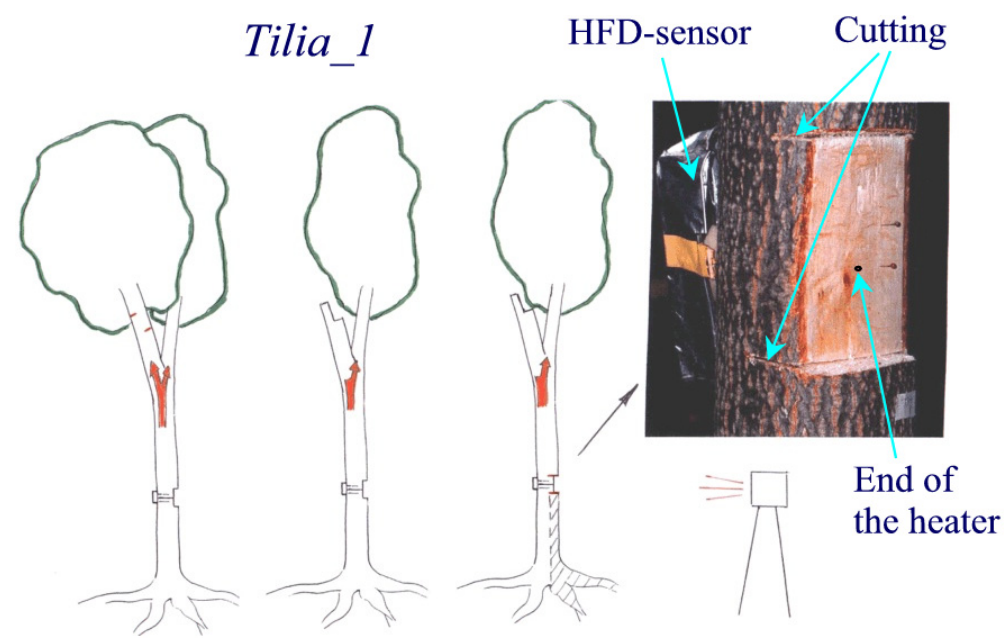

Figure 2. Schemes of complex treatments carried out with Tilia_1, showing cutting the upper branch (the left panel), removing the upper branch (middle panel) and cuttings of the stem just above and below of smoothed surface of the stem, prepared for IR-images (the right panel with photo). The radial sensor was displaced on the stem below the cut and removed branch. Orange arrows show distribution of flow, moved through the left part of the stem.

\section{The heater was switched off at 17.22:}
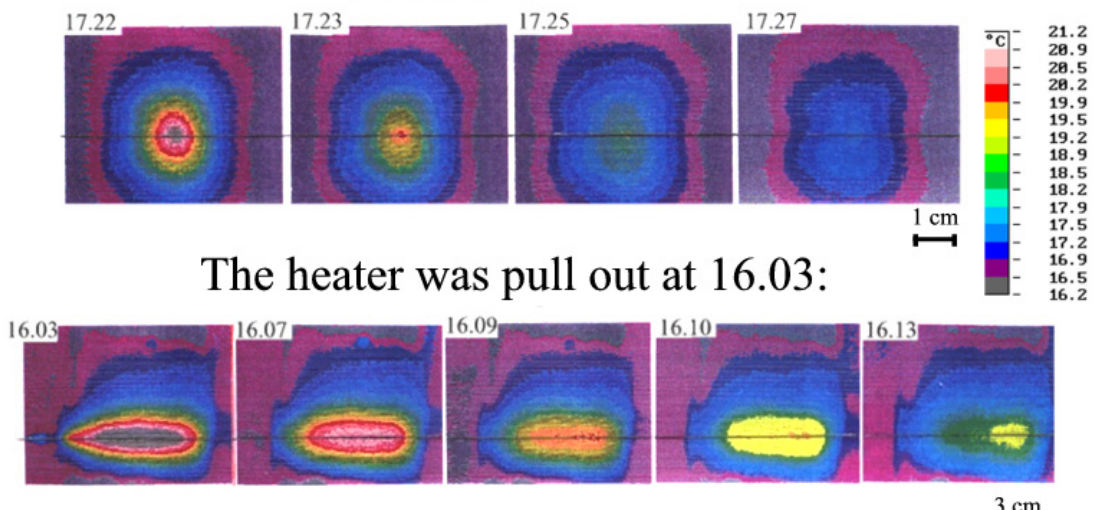

$3 \mathrm{~cm}$

Figure 3. Frontal (upper panel - Tilia_1) and radial (lower panel - Tilia_2) views of the heat field around the linear heater showing it disappearing from the moments, when the heater was switched off (upper panel) or removed from the stem (lower panel) in condition of zero-flow. 
together with the hot point originally identical with the heater axis (Fig. 3, upper images for differences).

On the other hand the same picture illustrates the principle of the HPV method [9, 10, 14, 24], which is based on recording the time over which the peak temperature moves across a certain distance.

Displacement of the hot spot out of its original position violates one of the main principles of the HFD method (constant power supply to the heater) and thus sap flow data calculated after switching off the heating become unrealistic. Similarly it fits also to heat dissipation method for sap flow measurements [7], based on simultaneous measurement of heated needle compared to non-heated ones. In practice it is rather difficult sometimes to distinguish short-term non-stable conditions (without heating), if analyzing only calculated sap flow data (like shown on Fig. 4, lower panels). In such cases it is very useful also to analyze records of temperature differences, where continuous power-supply and moments of its interruptions can be very well distinguished.

Sap flow could be correctly calculated after 3-5 min of continuous power supply due to rather quick establishment of temperature gradients around the heater (Fig. 4, lower images) and especially due to applying their ratio for sap flow calculations. This is because the point with maximum temperature stays at the same place (at the axis of the heater) and constantly generates the heat field. The heat field started to acquire a typical configuration according to existing sap flow rates just from the beginning of heating.

\subsubsection{Radial view under switching on the heating}

IR-images demonstrate radial patterns of flow through the whole stem section due to application of the long heater. Various deformation of the heat field in different xylem depths was recorded by both measuring techniques after switching on the heater (Fig. 5). Realistic radial patterns of flow can again be obtained after 3-5 min of continuous heating (Fig. 5, lower panels). The heat field was no more symmetrical around the heater axis as under zero flow (Fig. 3, lower images for differences), but it was moved upwards by the moving sap, especially in places with high flow rates. The "hot line" deviated from the heater axis, especially in the outer sapwood layers, while little deviation was observed in deeper sapwood (close to the heartwood): the line remained identical with the heater axis near the pith. Both measuring techniques also confirmed certain asymmetry of the treated stem, the left side of which (where thermocouples of the sensor were placed) was slightly wider than the right one.

\subsection{Cutting experiments}

\subsubsection{Tilia_2}

\subsubsection{Cutting above the sensor at $15.15 \mathrm{~h}$} (Fig. 1, middle panel)

Heat field responded extremely fast to the destructive treatment, so that its changes in seconds were recorded. The field started loosing its normal (previously described) form immediately after the cut at the observed stem side and changed it to an irregular and opposite one representing a downward movement (Fig. 6A). The abrupt decrease of flow till negative values was simultaneously recorded also by thermocouples of the flow sensor. Sap flow reached maximum negative values within 3 min after the cut, which were especially pronounced in sapwood layers, where the flow was higher before (Fig. 6A).

Concerning the measured place at the stem, we must consider the complete change of its pressure situation during its experimental treatment. The cut represent an abrupt separation of the sink (foliage) from the source of water (roots/soil). This caused replacing the usual negative water potential of foliage by values close to zero (i.e., to the atmospheric pressure) at the cut surface. Due to this change, roots (holding their original water potential) started to suck down water from the stem. But the free stem water storage was very small at the stem segment between the cut surface and the heater, therefore flow gradually declined there and finally approached zero. This procedure down to complete flow cessation in all xylem layers took 13 min (Fig. 6A, lower panels).

It was shown earlier, that integrated sap flow corresponds to changes in the stem water content before and after the cut [5]. The water columns in the tree conduits act like an elastic string being cut apart. The presented results confirm a very similar situation with simultaneous upward and downward sap movement, occurring when an aqueous solution under atmospheric pressure was applied into the hole drilled in stems during staining experiments [6]. However (as it was visible on IR-images), sap continued to move normally upwards at the opposite (not damaged) side of the stem at the same time, what indicated tangential stem segmentation.

\subsubsection{Cutting below the sensor at $15.38 \mathrm{~h}$ (Fig. 1, middle panel)}

An increase of flow was recorded by the IR-camera in the medium sapwood layers within the first minutes this time (Fig. 6B). A small flow increase was also simultaneously recorded at the opposite stem side, particularly in the inner (xylem) sapwood layers (close to pith) by the HFD-sensor (Fig. 6B, lower panels). Concerning the measured place, the cutting now produced an abrupt separation of the water source from its sink. This simultaneously released the soil-root resistance and increased the gradient of water potential between leaves and the plane of cutting. Also in this case an apparent elastic behavior of the xylem conduits was observed. The flow slowly approached zero then (this time in all xylem layers of the whole stem) again due to limited stem water storage.

\subsubsection{Tilia_1}

\subsubsection{Cutting (step 1) and removing (step 2) the branch above the sensor (Fig. 2, left and middle panels)}

Abrupt decrease of flow in outer xylem layers in the main stem $5 \mathrm{~m}$ below the cut branch within 3 first minutes was recorded by the HFD sensor (Fig. 7, middle upper panel). Then an increase of flow occurred there in the same layers within the next $8 \mathrm{~min}$. 
The heater was switched off at $16^{18}$
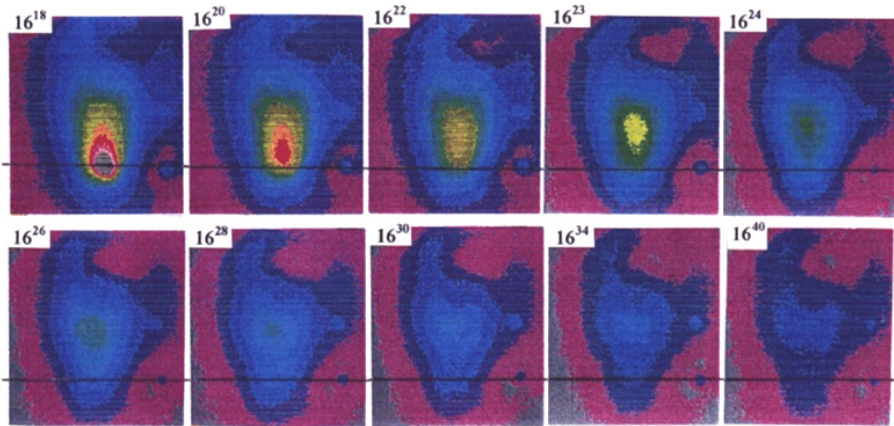

The heater was switched on at $16^{41}$ :
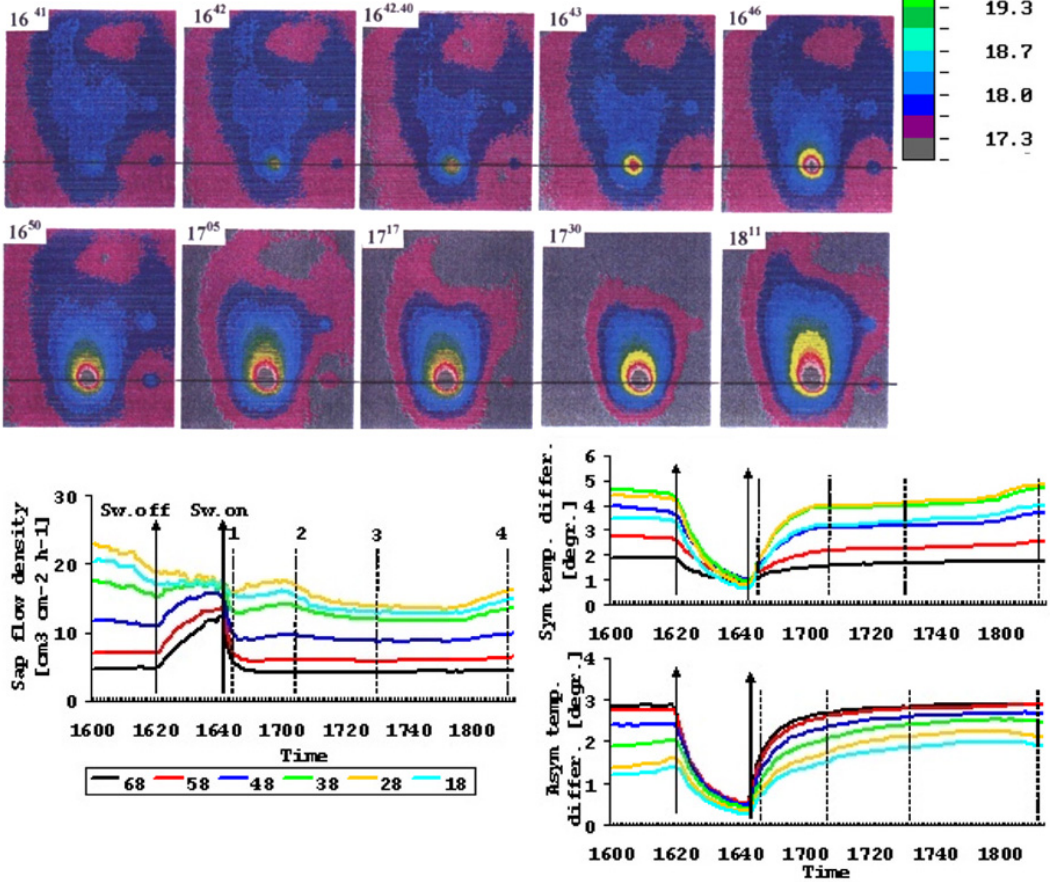

22.0

21.3

29.7

20.0

19.3

18. 7

18.8

17.3

Figure 4. Frontal IR-images of the heat field around the linear heater in stem of Tilia_l for periods when the heater was switched off (upper panel) and switched on (middle panel) under conditions of moving sap. Dynamics of sap flow in different xylem depths as well as temperature differences, recorded by the HFD-sensor from the opposite side of the stem during this period and used for calculation of sap flow, are presented in lower panel. Vertical lines with numbers mark periods with different sap flow rates, corresponding to IR-images made at time periods: $16^{41}, 17^{05}$ $17^{30}$ and $18^{11}$. Distances between the heater and two nails, heated by fingers for reference, are equal to $3 \mathrm{~cm}$ each (see also Fig. 1 for details).
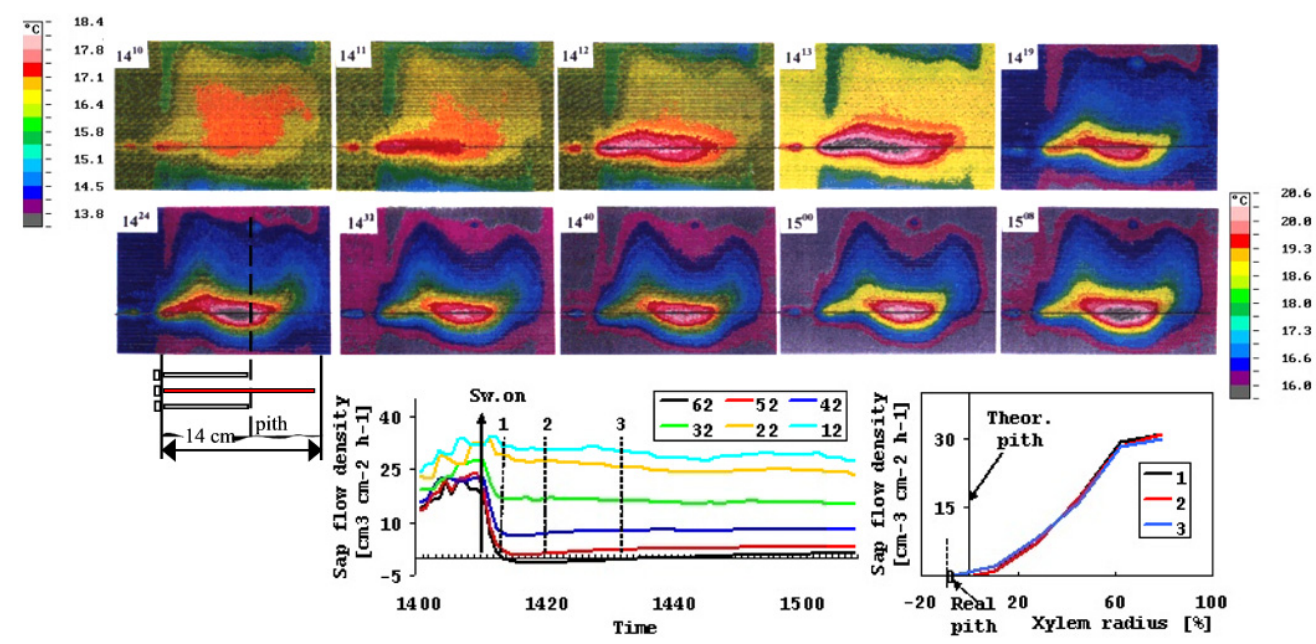
on. Sap flow dynamics in different xylem depths, recorded by the radial sensor during the same time period, are presented in left lower panel and radial patterns of flow for periods marked by vertical lines with numbers are presented in right lower panel. Positioning of theoretical (equal to half of $\mathrm{R}_{\mathrm{xyl}}$ ) and real (found after cutting) pith is marked in the last graph too. 


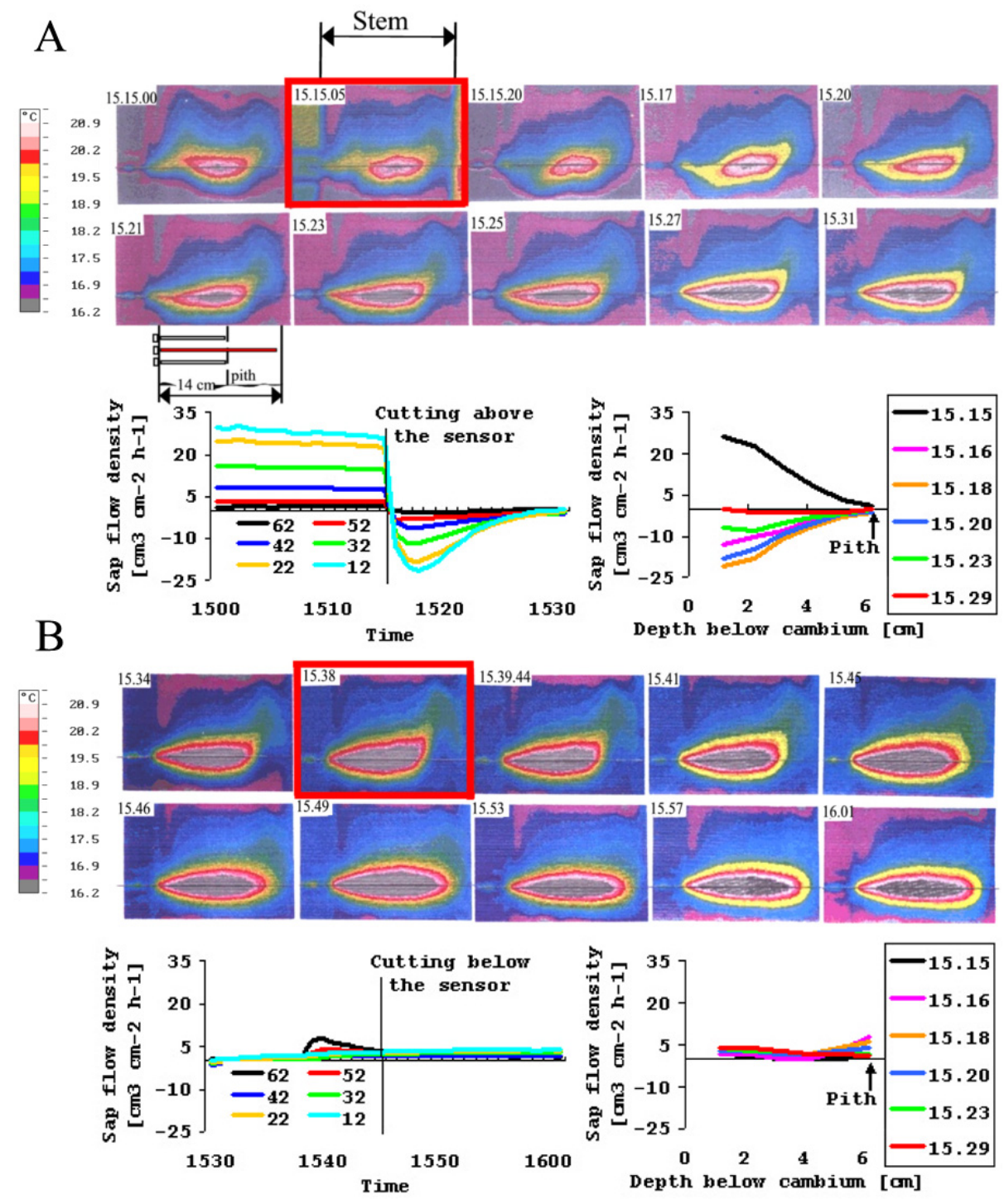

Figure 6. (A) Radial IR-images of the heat field along the linear heater after stem cutting in Tilia 2 above the radial sensor (Fig. 1, middle panel). Position of the sensor in the stem is shown schematically below IR-image, observed at $15^{2} \bar{T}$. IR-image, marked by red frame, corresponds to $1 \mathrm{~s}$ after cutting. Changing sap flow dynamics in different xylem depths as well as radial patterns corresponded to different time periods before and after cutting are shown in the left and the right lower panels, respectively. (B) Radial IR-images of heat field around the linear heater, showing it changing after stem cutting in Tilia_2 below the heater (Fig. 1, middle panel). IR-image, marked by red frame, corresponds to moment of cutting. Changing sap flow dynamics in different xylem depths as well as radial patterns corresponded to different time periods before and after cutting is shown in the left and the right lower panels, respectively.

Under such conditions some flow apparently still existed between both partially separated branch parts across $25 \mathrm{~cm}$ long part of the branch still staying in its original position (Fig. 2, left panel) and part of flow also passed through the measured part of the stem to the second big upper branch. The radial pattern of flow changed after its following increase: it became lower in the outer xylem layers but a little higher in inner xylem layers apparently due to redistribution of flow in xylem. It is interesting to compare this situation with the branch cut highly above (around $5 \mathrm{~m}$ ) the sensor to the cutting experiment on Tilia_2 with the cut closely above $(20 \mathrm{~cm})$ the sensor on the stem.
No flow was recorded by the sensor after cut there (Fig. 6A). Abrupt reaction on cutting also differed: here some low positive flow continued after cutting (Fig. 7), while a negative flow occurred in case of stem cutting just above sensor (Fig. 6A).

No visible change of the heat field was observed by the IRcamera during this treatment (Fig. 7). Obviously, outer xylem layers (where we observed the IR-images) were connected presumably with the second upper branch, which was not damaged.

Gradual decrease of sap flow in outer and middle xylem layers was observed at the left stem side within the next 12 min when the cut branch was removed (Fig. 7, lower left panels). 

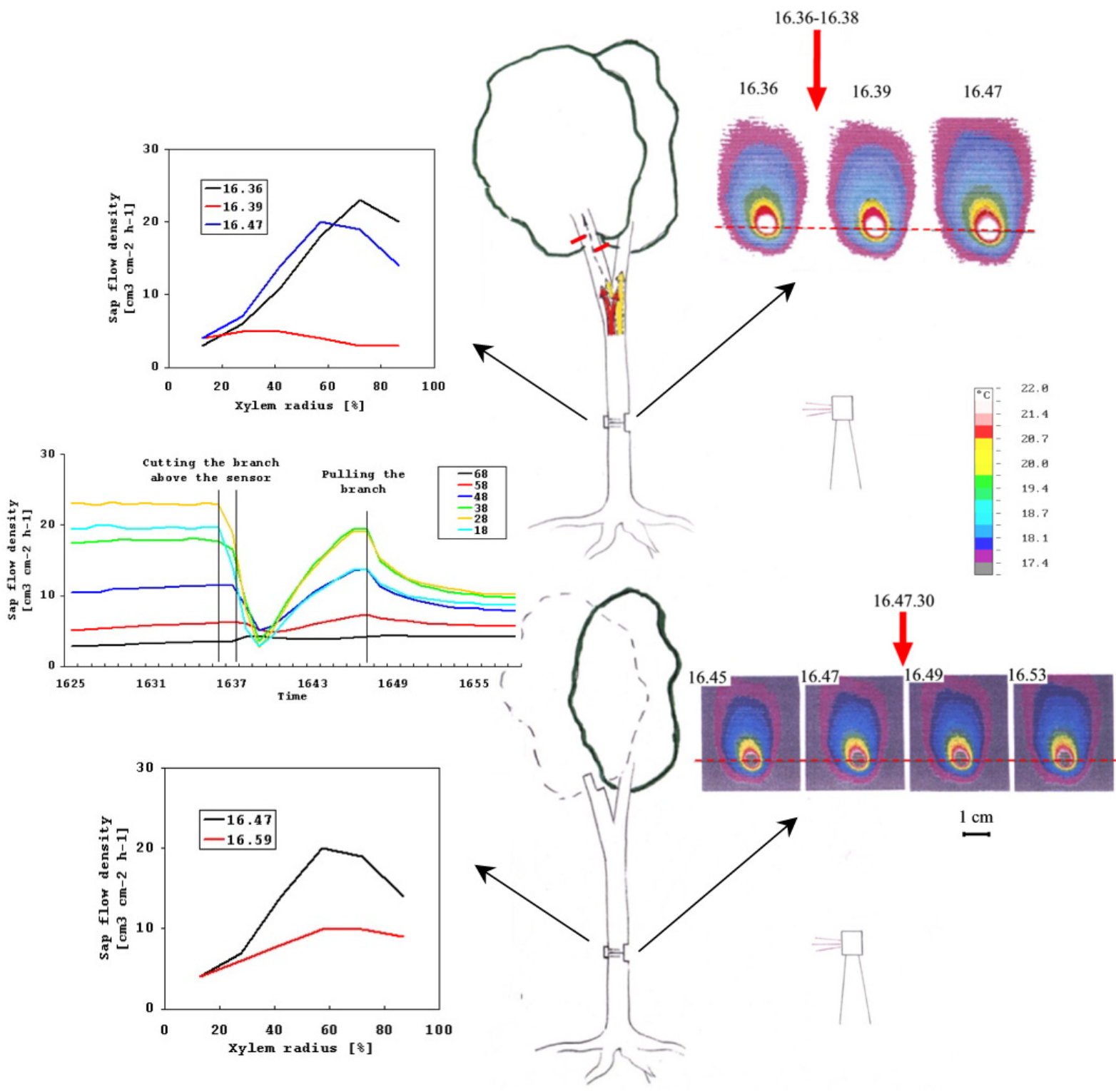

Figure 7. Scheme of Tilia_1 (middle upper panel) showing cutting of the upper branch, situated above the radial sensor with positioning of the radial sensor and smoothed surface from the opposite stem side, prepared for IR-images. Orange and yellow arrows show distribution of flow, moving through each part of the stem to both branches. Scheme of Tilia_l (middle lower panel) showing removing the upper branch, situated above the radial sensor. Radial patterns of sap flow and sap flow dynamics in different xylem depths, recorded by the radial profile sensor in the left stem side, and IR-images of the smoothed surface of the right stem side, recorded by the IR-camera for the same time period before and after cuttings or branch removing, are presented on the left and the right panels, respectively. Red arrows show periods cutting or removing the branch.

The flow decreased here mostly in outer xylem layers. The remaining fraction of flow was obviously related to the flow moving from roots situated below this side to the second upper branch. The IR-images showed additional enlargement of heat field with slightly increasing flow at the side with the IRcamera, although it was observed during later afternoon. This could be related with better illumination of the second branch after removing the first one.

\subsubsection{Cutting the stem below (step 3) and above (step 4) the heater from the side, where IR-images were observed (Fig. 8)}

The reaction of the tree, recorded by the sap flow sensor from the opposite side of the stem, followed rather similar tendency in both cutting events: the decrease in flow rate was followed by its gradual increase. The decreases of flow after cuttings may 


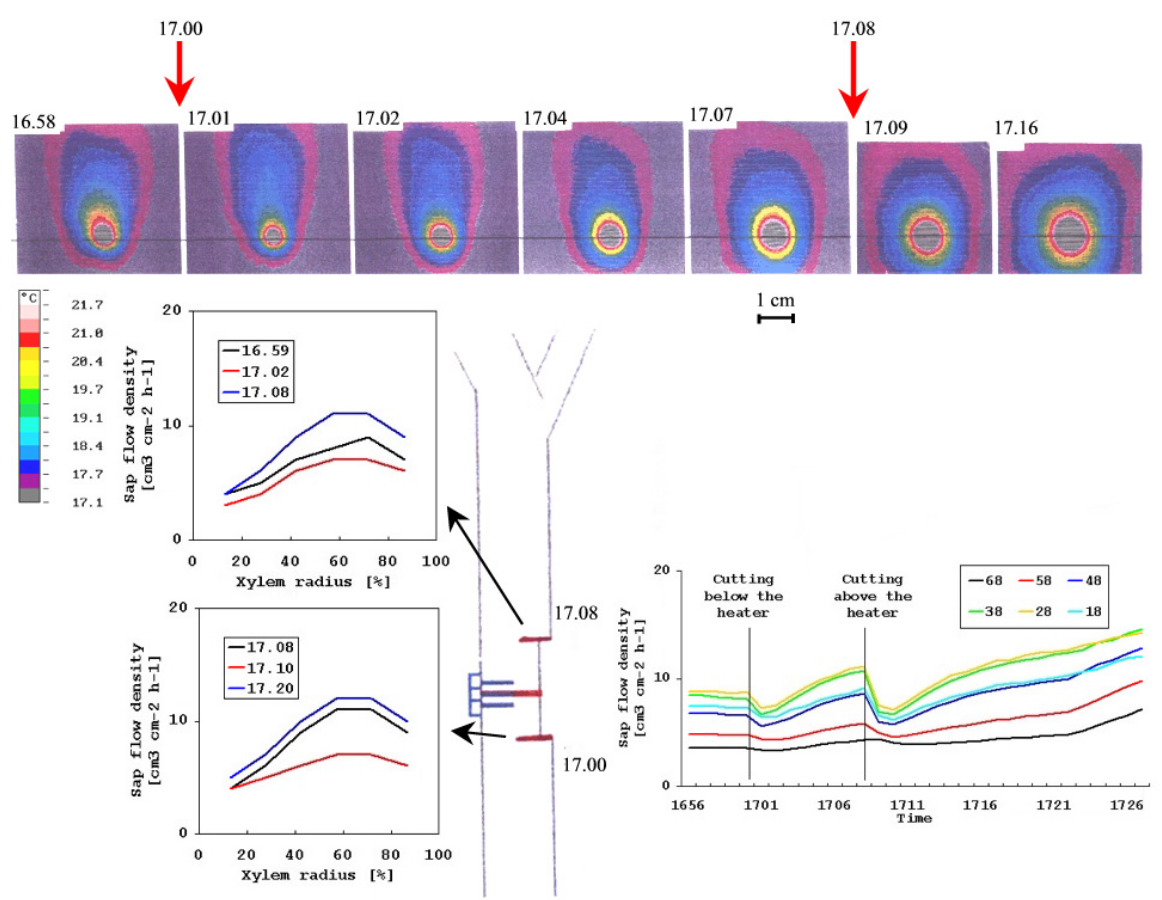

Figure 8. IR-images of the smoothed surface of the right stem side of Tilia_l (upper panel) before and after cuttings of the stem (marked by red arrows with time) below and above the heater from the right stem side (scheme in lower middle panel). Sap flow dynamics (right) as well as radial patterns of sap flow (left) in different xylem depths, recorded by the radial profile sensor in the left stem side for the same time period before and after cuttings are presented on the graphs.

tentatively be explained as a consequence of redistribution of tensile forces. The followed increases of flow could be explained by a decreasing of conducting pathways from side of cutting, drained by the same sink (i.e., leaf area). So, only pathways from opposite side of stem (where the radial sensor was placed) can be used after cuttings for water supply to the second branch.

IR-images during these treatments provide information on the side of stem cutting below the heater: similar as in the case with Tilia_2 (Fig. 6, upper panel) we also could see a "shock" of the heat field, caused by severing. The heat field was also abruptly disturbed here, but by different manner: it became longer and narrower, especially closely above the heater.

This could correspond to short abrupt increasing of flow due to sudden release of root-soil resistance and increase of the gradient of water potential between foliage and cut place at the same time (similar to cutting below the sensor in Tilia_2Fig. 6, lower panel).

The following IR-images (Fig. 8) demonstrate that the inner part of the heat field started to enlarge then and the eccentricity of the ellipses became smaller, indicating decrease of flow rates with depletion of the water storage in the remaining part of the stem. The upper part of the heat field slowly contracted. The flow stopped completely after the next cutting above the heater. The heat field continued to enlarge gradually until it reached the equilibrium (Fig. 8, IR-images). Finally, the form of the ellipse stabilized, what evidently occurred, when the heat field became determined by anisotropy (axial to tangential) heat conductivities only (Fig. 8, last right image). This situation occurred in contrast to that one, when the sink was deleted abruptly first (Fig. 6, upper panel: abrupt negative flow was observed). Responses of flow on abrupt environmental changes, caused by experimental treatments, as well as presence of flow redistribution in remaining xylem pathways were similar to those, described earlier for spruce and lime trees $[17,18]$.

Summarized pictures of sap flow dynamics and changing radial patterns of flow during this short (less than $1 \mathrm{~h}$ ) cutting experiments are shown in Figure 9, where sap flow dynamics in different xylem layers is presented in Figure 9A and simplified schemes of the tree canopy (sink of water) connected through sapwood of the stem with roots (source of water) are shown in Figure 9B. Each stem side supplied with water both opposite parts of the canopy through both opposite sides of the stem from corresponding water sources. (1) Before the experiments the situation on the opposite sides of the lime stem was as follows: some flow existed on the left stem side (which was recorded by the HFD-sensor: radial pattern of flow is shown). Similar flow took place also on the right side of the stem (where it was measured by the IR-camera) - (Figs. 9A and 9B, upper panel). (2) After deleting half of the sink (i.e., one of the two main branches - see middle panels in Fig. 9B) some pathways in both stem sides connected to the severed branch were inactivated. Earlier experiments showed, that stem at breast height is very sectorally connected with source of water (roots), but flow then spread wider in direction to foliage (Nadezhdina, unpublished). So, any radial cross-section in the stem sapwood is connected to each big branches, including those from the opposite side of stem concerning to the considering sector (Nadezhdina, unpublished). That is why the inactivated pathways were 
present in both stem sides after one branch removing (see middle panel in Fig. 9B). Flow from the side of the missing sink decreased significantly especially in outer xylem layers and the remaining flow moved to the second branch (Figs. 9A and 9B, middle panel). (3) When only the left stem side functioned partially (see lower panels in Fig. 9B - no flow occurred any more in the right stem side after its cutting), flow slightly increased there using the remaining part of water source (roots) towards the same sink (remaining branch). Magnitude of flow increase is dependent on water availability in soil in that case. If the IRimages for all 3 cases discussed above are compared, we can see two phenomena: first the flow increased after branch removing (due to better illumination of remaining branch) and then the flow stopped there completely, after the main stem was cut (and the heat field come again to equilibrium).

\subsection{Analytical characterization of IR heat field pattern}

Changes of heat field naturally well corresponded with the sap flow rates recorded by the HFD sap flow sensors. In general, behavior of the heat field under different sap flow rates was similar to that described by other authors $[1,2,8]$ and correspond to our previous descriptions, obtained by using series of thermocouples, arranged around a linear heater [15]. Deformation of the heat field clearly reflected radial changes in sap flow $[4,6,11,12,20,21]$. The information obtainable from the infrared images of the heat field was analyzed and analytical procedure was suggested toward improved tools for sap flow measurement.

Generally, it has to be stated, that reasonably complete mathematical description of the heat field pattern dynamics in a xylem structure is too complicated for practical use [3]. However a significant simplification may be possible. Under conditions of theoretically homogenous material (with equal heat conductivities in all directions), the heat field pattern would obtain the form of a circle (Fig. 10, upper panel). Under real conditions due to asymmetry of heat conductivities, caused by xylem structure, the iso-temperature profiles in thermographic pictures around the heated needle are arranged in the form of ellipses (Fig. 10, upper right scheme and lower left IRimage). Ratio of heat conductivities, $R$, in axial and tangential directions in stems is always higher than 1.The stem xylem is a complex material consisting mainly of cell-wall solid substance, water and air. These main fractions of the total xylem volume $\mathrm{V}$, marked as $\mathrm{V}_{\mathrm{x}}, \mathrm{V}_{\mathrm{w}}$ and $\mathrm{V}_{\mathrm{a}}$ have known heat conductivities, valid for all woody species $\left(\mathrm{k}_{\mathrm{xyl} \_\mathrm{ax}}=0.88 ; \mathrm{k}_{\mathrm{xyl} \_\mathrm{tg}}=\right.$ $\left.0.44 ; \mathrm{k}_{\mathrm{wat}}=0.59 ; \mathrm{k}_{\mathrm{air}}=0.024-[23]\right)$ and can be easily estimated e.g. on woody cores. Technical literature gives values for $\mathrm{R}$ between $1.6-2.5$ for partially dry wood $[13,22]$. Estimates for sapwood in live trees gave lower values of that ratio, from 1.2 to 1.7 for poplar, oak, spruce and pine (Cermak, unpublished).

Under zero-flow the ratio of the axes $(a / b)$ in IR-ellipses could also provide information on the asymmetry of heat conduction parallel and perpendicular to the stem axes. Values, readable from IR pictures (Fig. 10), confirm the volumetric estimates.

The ellipses follow the well known mathematical laws: they are described by two axes $-a$ and $b$, two focuses $F 1$ and $F 2$ and the center $M$. The distance from focus $F 1$ via any point $P$ on the ellipse to focus $F 2$ is equivalent to the twice length of the main bigger axis. This simply reflects the fact that heat, leaving focus $F 1$ in any direction and at any flow rates, will always be determined by the second focus $F 2$.

IR-images, shown in Figure 10, demonstrate, how the ellipses of iso-temperature profiles change with increasing sap flow rates. For zero-flow conditions the heating source is situated in the center of the ellipse (Fig. 10, left IR-image). When the sap starts to move, the center $M$ of the ellipse is carried upwards, because the asymmetric heat conductivity is compensated and the lower focus $F 1$ gradually approaches the heater (Fig. 10). Under higher sap flow rates it remains localized there, while the upper focus $F 2$ and the center of the ellipse $M$ continue to move upwards with increasing sap flow. At the same time the $b$-axis of the ellipse becomes smaller, satisfying the condition that eccentricity, $e$, of the ellipse (equal to the half of the distance between focuses) is increasing simultaneously (Fig. 10: $\left.e^{\prime, '}>e^{\prime \prime}>e^{\prime}\right)$. Intuitively one can imagine, that the heat cannot progress so far away perpendicular to the stem axis, because it is transported along the stem with the sap. It is well visible also, that definite zone of sensitivity for measurements exists around the heater depending on used power supply: isothermal profiles become bigger and lose their elliptical forms with increasing distances from the heater. So, some compromise should be found between applied power and sensor's geometry. Considering the mathematical properties of ellipses and adapting the measured IR-patterns of heat fields (particularly the eccentricity of ellipses) may therefore provide an important tool for further improving our knowledge on measuring sap flow rates, when using internal point heating. This strategy will be adapted in a forthcoming paper.

\section{CONCLUSIONS}

The selected field experiments on large trees with combined multi-point thermometer technique (applied in HFD-method) and IR-imaging technique allowed comparable evaluation of characteristic thermodynamic features of the heat field around a linear heater in tree stems under well defined experimental conditions. Both measurement techniques are invasive for trees, but to a different extent. Both methods are based on temperature measurements. While the IR-technique gives a full picture of the heat field distribution around the heater, the HFD measures only two distinct temperature gradients. The heat field on IR-images is shown in a wider environment from the heater, then with point sensor techniques. A special advantage of the direct IR-visualization of the heat field dynamics is that the cohesion properties of the xylem water can be intuitively interpreted and understood. The IR also shows directly the xylem anisotropy (axial and tangential), which could be quantified and depicted.

However, the IR-method measures the heat field in only one layer of observation (tangential or radial), while the HFD-technique can monitor the depth (many layers) simultaneously. HFD-method allows simultaneous measurements of sap flow in many compartments of a tree as well, what hardly could be achieved with IR-technique.

Comparison the HFD-method with IR-technique in situ confirmed the ability of the HFD for measurements of the bi-directional 
A

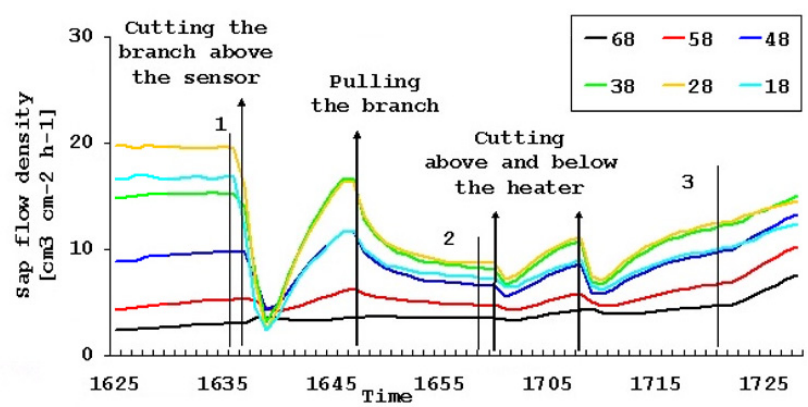

B
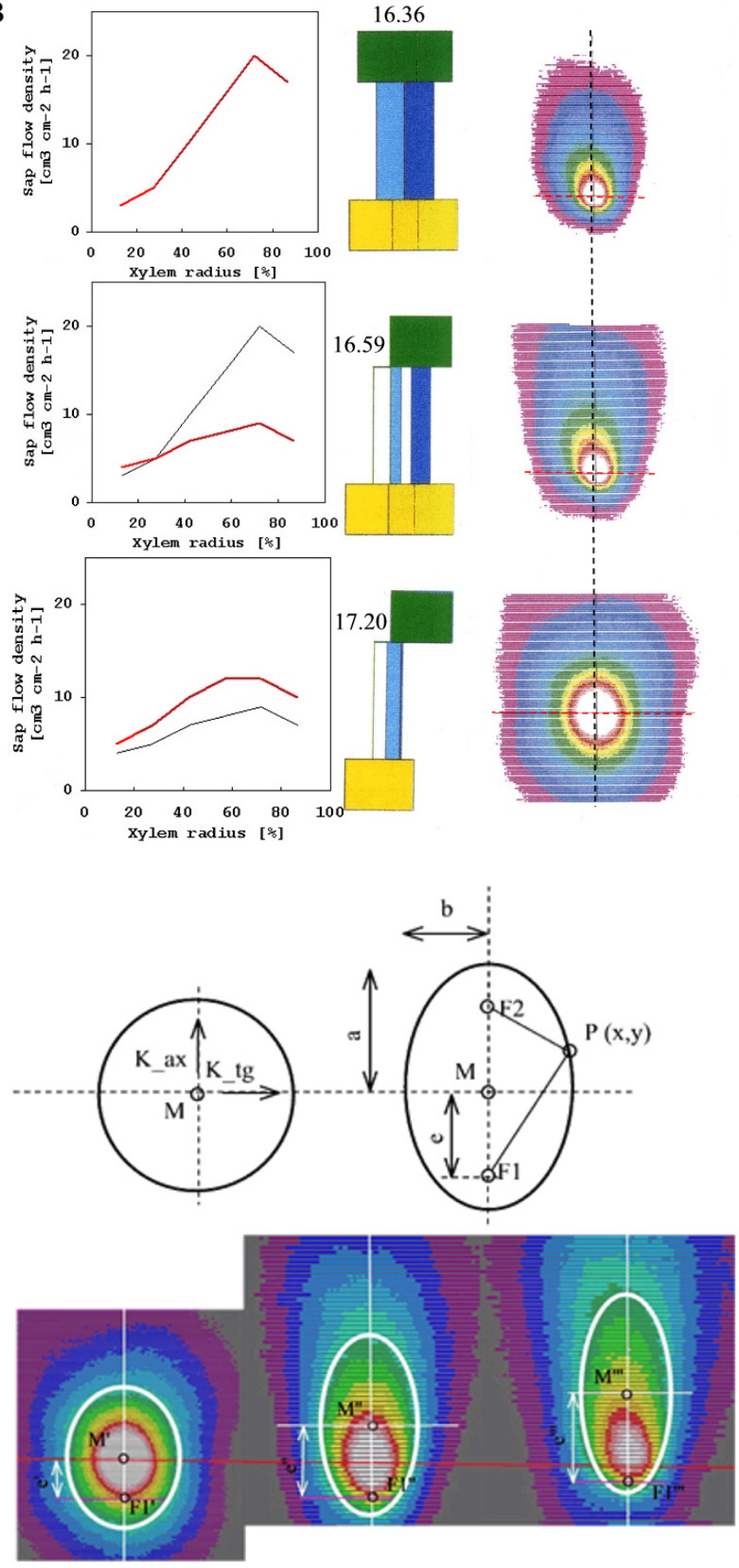

Figure 9. (A) Sap flow dynamics in different xylem depths, recorded by the radial sensor in the left side of the stem during complex treatments carried out with Tilia_l. Four vertical lines with arrow correspond to period of different treatments marked above them (see also Figs. 7 and 8). (B) Simplified schemes of complex treatments carried out with Tilia_l (Figs. 2, 7, 8 and 9A), showing tree before treatments (upper panels), after removing one upper (left) branch (middle panels) and cuttings of the right side of the stem (lower panels). All these three periods marked by vertical line with numbers on graph with sap flow dynamics (Fig. 9A). Parts of stem not filled by color present inactivated xylem vessels in both sides of the stem. Radial patterns, recorded by the radial sensor for chosen periods of the experiment are shown in the left side and IR-images of smoothed surface of the stem for the same moments - in the right side. IR-images represented only one measured point along stem radius- that one with maximum flow at the smoothed stem surface.

Figure 10. Theoretical schemes of a heat field in the stem xylem around a linear heater under zero-flow conditions (upper panel): it is a circle (left) under ideal conditions with equal heat conductivities in axial (K_ax) and tangential (K_tg) directions and an ellipse (right) in reality due to asymmetry in heat conductivities (K_ax $>$ K_tg) in tree stem. $M$ - center of a circle or an ellipse, $F 1, F 2$ - focuses of an ellipse, $a$ and $b$-main axes of an ellipse, $e$-eccentricity of an ellipse. IR-images of the heat field (lower panel) under zero-flow (left) and with increasing sap flow rates (middle and right images, respectively): numbers of inverted commas nearby letters mark situation with different increasing sap flow rates, starting from zero. Red horizontal line marks the axis of the heater. Scale: small axis (b1) of one of the ellipses under zero flow (drawn by white color in the left IR-image) is equal to $1 \mathrm{~cm}$. 
and extremely low flows (those approaching zero, such as resaturating flows at night). Fast responding and high sensitivity of the HFD-method to any changes within xylem pathways, demonstrated during severing experiments, also showed its capability for studies of tree architecture and function, including flow redistribution within trees.

Visualization of the heat field also allows evaluation of optimal positioning of the sap flow sensors. For this purpose the mathematical properties of the dynamics of heat field (via ellipses with different eccentricities) will have to be evaluated and the sensor geometry could be optimized in order to measure the relevant parameters.

Acknowledgements: This study was done within the project of Hahn-Meither Institute and analysed within the framework of WATERUSE project (EVK1-CT-2000-00079).

\section{REFERENCES}

[1] Anfodillo T., Sabatti M., Sigalotti G.B., Valentini R., An application of infrared thermal image to monitor water transport in plants, in: Carlomagno G.M., Corso C. (Eds.), Advanced Infrared Technology and Applications, Firenze, 1992, pp. 427-437.

[2] Anfodillo T., Sigalotti G.B., Tomasi M., Semenzato P., Valentini R., Application of thermal imaging in the study of sap flow in woody species. Plant Cell Environ. 16 (1993) 997-1001.

[3] Carslaw H.S., Jaeger J.C., Heat in Solids, Oxford University (Claredon) Press, 2nd Issue, 1962.

[4] Čermák J., Nadezhdina N., Sapwood as the scaling parameter - defining according to xylem water content or radial pattern of flow? Ann. Sci. For. 55 (1998) 509-521.

[5] Črmák J., Jeník J., Kučra J., Zidek V., Xylem water flow in a crack willow tree (Salix fragilis L.) in relation to diurnal changes of environment, Oecologia 64 (1984) 145-151.

[6] Čermák J., Cienciala E., Kučera J., Lindroth A., Hallgren J.E., Radial velocity profiles of water flow in stems of spruce and oak and response of spruce tree to severing, Tree Physiol. 10 (1992) 367-380.

[7] Granier A., A new method to measure the raw sap flux in the trunk of trees, Ann. Sci. For. 42 (1985) 193-200.

[8] Granier A., Anfodillo T., Sabatti M., Cochard H., Dreyer E., Tomasi M., Valentini R., Breda N., Axial and radial water flow in the trunks of oak trees: a quantitative and qualitative analysis, Tree Physiol. 14 (1994) 1383-1396.

[9] Huber B., Weitere quantitative Untersuchungen uber das Wasserleitungssystem der pflanzen, Jahrsblad des wissenschaftliche Botany 67 (1936) 877-959.
[10] Huber B., Schmidt E., Weitere thermoelektrische Untersuchungen uber den Transpirationsstrom der Baume, Tharandter Forstliche Jahrsblad 87 (1936) 369-412.

[11] Jimenez M.S., Nadezhdina N., Čermák J., Morales D., Radial variation in sap flow rate in five laurel forest tree species in Tenerife, Canary Islands, Tree Physiol. 20 (2000) 1149-1156.

[12] Lambs L., Muller E., Sap flow and water transfer in the Garrone River riparian woodland, France: first results on poplar and willow, Ann. For. Sci. 59 (2002) 301-315.

[13] MacLean J.D., Thermal Conductivity of Wood, Heating, Piping, and Air Conditioning 13 (1941) 380-391.

[14] Marshall D.C., Measurements of sap flow in conifers by heat transport, Plant Physiol. 33 (1958) 385-396.

[15] Nadezhdina N., Temperature gradients around a linear heater in stems due to mowing sap, in: Cermak J., Nadezhdina N. (Eds.), Measuring Sap Flow in Intact Plants, Proc. of 4th. Int. Workshop, Zidlochovice, Czech Republic, IUFRO Publications, Brno, Czech Republic, Publishing House of Mendel University, 1998, pp. 65-71.

[16] Nadezhdina N., Cermák J., The technique and instrumentation for estimation the sap flow rate in plants (in Czech), Patent No. 286438 (PV-1587-98), 1998.

[17] Nadezhdina N., Čermák J., Responses of Sap flow rate along tree stem and coarse root radii to changes of water supply, in: Stokes A. (Ed.), The Supporting Roots of Trees and Woody Plants: Form, Function and Physiology. Developments in Plant and Soil Sciences, Vol. 87, Kluwer Academic Publishers, 2000, pp. 227-238.

[18] Nadezhdina N., Cermák J., Responses of sap flow in spruce roots to mechanical injury, in: Klimo E., Hager H., Kulhavy J. (Eds.), Spruce Monocultures in Central Europe: Problems and Prospects, EFI Proc. No. 33, 2000, pp. 167-175.

[19] Nadezhdina N., Cermák J., Nadezhdin V., Heat field deformation method for sap flow measurements, in: Cermák J., Nadezhdina N. (Eds.), Measuring Sap Flow in Intact Plants, Proc. of 4th. Int. Workshop, Zidlochovice, Czech Republic, IUFRO Publications, Brno, Czech Republic, Publishing House of Mendel University, 1998, pp. 72-92.

[20] Nadezhdina N., Črmák J., Morales D., Jimenez M.S., Raschi A., Tognetti R., Ferreira M.J., Variations in conducting patterns of trees growing in three Mediterranean countries and relations to crown development, in: Radoglu K. (Ed.), Forest Research: a Challenge for an Integrated European Approach, Proc. of the Int. Conf., Thessaloniki, Greece, 2001, pp. 507-512.

[21] Nadezhdina N., Črmák J., Ceulemans R., Radial patterns of sap flow in woody stems of dominant and understory species: scaling errors associated with positioning of sensors, Tree Physiol. 22 (2002) 907-918.

[22] Perelygin L.M., Ugolev B.N., Woodscience (in Russian), Lesnaja Promyschlennost, Moskva, 1971.

[23] Siau J.F., Wood: Influence of Moisture on Physical Properties, Virginia Polytechnic Institute and State University, 1995.

[24] Swanson R.H., Numerical and experimental analysis of implantedprobe heat-pulse theory, Ph.D. thesis, University Alberta, Canada, 1983. 